\title{
O ENTENDIMENTO DE UMA PROPOSIÇÃO NO DOMÍNIO DA GRAMÁTICA
}

\section{The understanding of a proposition in the domain of the grammar}

\section{Mariluze Ferreira de Andrade e Silva}

Professora da Universidade Federal de São João Del-Rei (UFSJ), Laboratório de Lógica e Epistemologia, Minas Gerais - Brasil, e-mail: mariluze@ufsj.edu.br

\begin{abstract}
Resumo
Wittgenstein divide a Gramática filosófica $(1974 / 2003)^{1}$ em duas partes. A primeira trata de "A proposição e seu sentido" e a segunda apresenta uma investigação "Sobre a lógica e a matemática". A primeira, cap. I, q. 1-13, aborda o tema sobre "entender uma proposição" relacionada às regras do jogo de xadrez. Este estudo analisa as 13 questões, com o objetivo de esclarecer o domínio do uso, na sentença, do conceito 'entender', no contexto da gramática, fazendo analogia com o uso das regras do xadrez, no tabuleiro.
\end{abstract}

Palavras-chave: Wittgenstein. Gramática filosófica. Filosofia analítica.

A primeira data refere-se à obra original e a segunda à tradução para o Português. 


\section{Abstract}

Wittgenstein divides the Philosophical Grammar (1974/2003) in two parts. The first refers to "The proposition and its sense" and the second presents a research "On the logic and mathematics". The first ch. I, q. 1-13, approaches the theme about "to understand a proposition" related to the rules of the game of Chess. This study analyzes the 13 subjects, with the objective of clearing the domain of the use, in the sentence, of the concept 'understand', in the context of the grammar, making analogy with the use of the rules of the Chess, in the board.

Keywords: Wittgenstein. Philosophical grammar. Analytic philosophy.

TLP: Tractatus lógico-philosophicus

PI: Philosophical investigations

\section{INTRODUÇÃO}

O que se coloca nesse trabalho como objeto de investigação é o uso do conceito 'entender', no contexto da gramática, e a sua analogia com as regras do jogo de xadrez. O desenvolvimento dessa questão, entretanto, pressupõe clareza quanto ao termo 'gramática', do ponto de vista de Wittgenstein.

É comum definirmos o termo 'gramática', como sendo um conjunto de regras usado para falar e escrever corretamente uma língua. Desse ponto de vista, a maioria dos linguistas está de comum acordo que, dispensando as regras, teremos, enquanto ouvintes, dificuldades para compreender o falante, diante da agramaticalidade que a proposição pode apresentar durante o seu proferimento. Wittgenstein não exclui essa definição de gramática, mas lhe dá definições de usos mais ampliados, seguindo o curso das suas investigações voltadas para a linguagem filosófica.

O primeiro Wittgenstein recomenda cautela quanto ao uso da gramática normativa, uma vez que a preocupação com a gramática normativa que impõe regras ao uso das proposições pode disfarçar a sua forma lógica. Assim, 
para evitar esses equívocos, devemos empregar uma notação que os exclua, não empregando o mesmo sinal em símbolos diferentes e não empregando superficialmente da mesma maneira sinais que designem de maneiras diferentes. Uma notação, portanto, que obedeça à gramática lógica - à sintaxe lógica (TLP, 3.325).

Nesse momento, ele está se referindo a uma gramática cujas regras dão suporte à sintaxe lógica. Em outro momento, a gramática é usada para alcançar as regras constitutivas da linguagem, a investigação e organização dessas regras. Assim, conforme Wittgenstein,

pode-se dizer agora: "É o modo como se tem a fórmula em mente que vai determinar quais passagens devem ser feitas". Qual é o critério para o modo como se tem a fórmula em mente? Talvez o modo como a usamos constantemente, o modo como nos foi ensinado a usá-la. Dizemos, p. ex., a alguém que usa um signo que nos é desconhecido: "Se você com ' $x$ !2 tem em mente $x^{2}$, então obtem para y este valor; se tem em mente $2 \mathrm{x}$, obtem aquele valor. " - pergunte agora a si mesmo: Como se faz para tem em mente um ou outro com o signo 'x!2”? É assim, portanto, que terem-mente pode, de antemão, determinar as passagens (PI, § 190).

Entendendo que as questões lógicas são gramaticais e dizem respeito a regras para o uso das palavras, Wittgenstein continuou usando o termo 'lógica da linguagem' na mesma acepção que usava o termo 'gramática' como se pode conferir nos $\S \S$ seguintes de Investigações filosóficas:

O que denomina, p. ex., a palavra 'isso' no jogo de linguagem ou a palavra 'isto' na explicação ostensiva "Isto se chama...." - Se não se quer provocar confusão, o melhor é não dizer que estas palavras denominam alguma coisa [...] (PI, §38).

Por isso nossa reflexão é uma reflexão gramatical. E esta reflexão ilumina o nosso problema, removendo mal-entendidos (PI, § 90).

Mas isto pode agora dar a impressão de que existe algo assim como uma última análise de nossas formas de linguagem, portanto, uma forma de expressão perfeitamente decomposta. [...] Isto pode ser dito também da seguinte forma: nós eliminamos mal-entendidos ao tornarmos nossa expressão mais exata: pode parecer, no entanto, que aspiramos a um estado determinado, à exatidão perfeita e que isto é a meta propriamente dita da nossa investigação (PI, §91).

"A essência nos é oculta". Eis a forma que nosso problema assume agora. Nós perguntamos: "O que é linguagem?" "O que é proposição?" 
E a resposta a estas questões deve ser dada de uma vez por todas e independente de qualquer experiência ulterior (PI §92).

Alguém poderia dizer "Uma proposição é o que há de mais trivial no mundo", e um outro: "Uma proposição - é algo muito esquisito!" - E este simplesmente não é capaz de verificar como as proposições funcionam, porque as formas de nosso modo de falar, que dizem respeito às proposições e ao pensar, o atrapalham (PI §93).

Prossegue nessa mesma linha em outros $\S \S$ como podemos conferir no $\$ 345$.

Foi nesse estágio que Wittgenstein passou a se referir à gramática de palavras, expressões, proposições e sentenças e incluiu a gramática de estados e processos. Wittgenstein manteve a concepção de que é a expressão linguística que possui uma gramática de acordo com o seu modo de utilização. As "regras gramaticais" são padrões para o uso correto de expressões que determinam seu significado. Dar o significado de uma palavra é especificar sua gramática.

Na Gramática filosófica, cap. I, q. 1-13, Wittgenstein aborda o tema sobre "entender uma proposição". Analisa 13 questões sobre a gramática do conceito "entender' com o objetivo de esclarecer o que significa, do ponto de vista da gramática, "entender uma proposição", fazendo analogia com o uso das regras do jogo de xadrez.

Desenvolveremos, a seguir, a investigação dessas 13 questões, conforme apresenta Wittgenstein.

\section{Questão 1. O que significa entender e entender uma proposição}

Conforme Wittgenstein, de modo geral, 'entender' significa "tomar como um todo", por isso entendemos a proposição porque ela é um pensamento completo, tomado como um todo, a exemplo do movimento de uma peça do jogo de xadrez. Porém, o conceito 'entender' como fenômeno que ocorre enquanto ouvimos o proferimento de uma proposição em uma linguagem familiar, nos leva a questionar se o entendimento ocorre simultaneamente ao proferimento ou após o proferimento completo de uma proposição.

O entendimento, segundo Wittgenstein, é essencial porque ele nos diz "do que se trata". No entanto, entendemos coisas diferentes sobre o mesmo assunto, o que nos leva a crer que o conceito 'entender' 
não é rígido. Disso decorre que o entendimento de uma proposição pode, às vezes, ser a tradução de um signo para outro, como outro modo de representação. Por exemplo: traduzo o signo 'casa' da proposição: "Moro em uma linda casa" pelo signo 'residência': "Moro em uma linda residência". A tradução do signo é outro modo de representar a proposição. Tendo isso em vista, Wittgenstein afirma que saber usar a palavra, na sentença, é o mesmo que saber usar as regras do xadrez, no tabuleiro e, nesse caso, os signos são usados como veículos de entendimento.

Diante da possibilidade de mudar o entendimento da proposição quando se substitui um signo pelo outro, Wittgenstein problematiza o uso do conceito 'entender': "Como se pode falar sobre 'entender' ou 'não entender' uma proposição? Por acaso não é uma proposição até ser entendida?" Essas questões nos põem a caminho da investigação do conceito 'entender' uma proposição pela óptica da gramática.

Wittgenstein apresenta várias possibilidades de uso desse conceito, conforme contexto gramatical, sendo que o seu entendimento mais amplo se aplica a uma proposição ou pensamento completo. Não podemos obscurecer que entendemos coisas que não são, necessariamente, uma proposição, no sentido tradicional. Na verdade, entendemos o que tem sentido, independentemente de ser ou não uma proposição que expressa um pensamento completo. O exemplo de Wittgenstein ilustra a compreensão da variação do uso desse conceito: "Uma caixa de bombom tem sentido, para mim, e eu entendo o seu significado a partir do seu sentido." Nesse exemplo, Wittgenstein mostra outro lado da questão: entender o que significa a partir do sentido. Uma caixa de bombom não é uma proposição, mas poderá ser desde que tenha em si mesma um sentido que relacione o seu significado ao entendimento de uma caixa de bombom. Entendemos uma proposição porque ela tem um pensamento completo e um sentido. Mas para entender uma proposição, segundo Wittgenstein, precisamos saber o que é uma proposição e quando começamos a entendê-la.

A questão de Wittgenstein: "Entendemos uma proposição quando ela está em construção ou quando ela está completa?" encontra resposta no entendimento do movimento do cavalo, no jogo de xadrez. Essa peça é executada por dois movimentos: um direto e um oblíquo. Isso é uma regra do jogo e não se pode entender meio movimento do cavalo como se entende meio pão porque há diferença de entendimento do termo 'meio' nos dois casos, que não é de grau. Nesse caso, o entendimento é a coisa essencial enquanto os signos são algo inessencial. Assim se expressa Wittgenstein (2003, p. 27), em Gramática filosófica: 
Entender não começa apenas com uma proposição, com uma proposição inteira? Você pode entender meia proposição? - Meia proposição não é uma proposição inteira. - Mas o que significa a pergunta talvez possa ser entendido da seguinte maneira. Suponha que o movimento do cavalo no jogo de xadrez sempre foi executado por dois movimentos da peça, um direto e um oblíquo; então, poder-se-ia dizer: "No xadrez não há meios movimentos do cavalo", que significa: a relação entre meio movimento e movimento inteiro do cavalo não é a mesma que existe entre meio pão e o pão inteiro. Queremos dizer que não é uma diferença de grau.

Quando falamos em 'entender' ou 'não entender' uma proposição, parece que estamos querendo dizer que um proferimento não é uma proposição enquanto não for entendido. Wittgenstein (2003, p. 27) coloca a seguinte questão:

Faz sentido apontar um grupo de árvores e perguntar: "Você entende o que esse grupo de árvores diz?". Em circunstâncias normais, não; mas não seria possível expressar um sentido por meio de um arranjo de árvores? Não poderia ser um código? Chamaríamos de "proposições" os grupos de árvores que entendêssemos; outros, que não entendêssemos, também, contanto que supuséssemos que quem as plantou tivesse entendido.

Parece que Wittgenstein (2003, p. 27) desconstrói o conceito tradicional de 'proposição', restrito a um pensamento completo, e o amplia a tudo que expressa sentido e significa algo, quando coloca as questões: "Você entende o que esse grupo de árvores diz?". Em circunstâncias normais, não; mas não seria possível expressar um sentido por meio de um arranjo de árvores? Não poderia ser um código?"

Além disso, parece que, para Wittgenstein (2003, p. 27), algo é uma proposição, independentemente do nosso entendimento, desde que suponhamos que quem diz que algo é uma proposição assim o entenda: “[...] chamaríamos de 'proposições' os grupos de árvores que entendêssemos; outros, que não entendêssemos, também, contanto que supuséssemos que quem as plantou tivesse entendido".

É importante para Wittgenstein, ter clareza sobre o que é uma proposição. Quando ele compara uma proposição com o movimento completo de uma peça do jogo de xadrez, nos informa que proposição é tudo aquilo que, completo em si mesmo, tem um sentido para nós. Esse seria o critério dado para entendermos algo como sendo uma proposição. 
A regra do jogo de xadrez prescreve que o movimento do cavalo se completa executando, no tabuleiro, um movimento direto e um oblíquo. Se executarmos apenas um dos movimentos, o sentido do movimento do cavalo fica incompreensível, porém executando os dois movimentos, o sentido se completa e temos o entendimento do movimento do cavalo. Nesse caso, o movimento completo seria um pensamento completo/proposição porque tem sentido relacionado ao significado do jogo e nos dá o entendimento do movimento da peça. Desse modo, o conceito de 'proposição' se amplia e se estende para o conceito de 'entender uma proposição'.

Assim, tanto uma caixa de bombom, como um conjunto de árvores com sentido completo para alguém, como o movimento completo de uma peça do jogo de xadrez podem expressar um pensamento completo e ser chamados de 'proposição' do mesmo modo que a proposição "João vai ao cinema".

Concluímos que para algo ser chamado proposição é suficiente ter um sentido completo e significar algo, independentemente do que seja.

\section{Questão 2. Entender os signos e a linguagem}

Wittgenstein (2003, p. 27-8) considera o entendimento como a coisa essencial e os signos como algo inessencial. Ele adverte que os signos não são usados para sermos entendidos pelos outros. Essa questão é problematizada da seguinte maneira:

suponha que a pergunta seja: 'O que você quer dizer com esse gesto?' e a resposta seja: 'Quero dizer que você deve ir embora'. A resposta não teria sido formulada mais corretamente: 'Quero dizer o que quero dizer com a sentença você deve ir embora.

É a sentença que expressa o que queremos dizer e não o signo, particularmente: "Quero dizer o que quero dizer com a sentença "você deve ir embora"".

Wittgenstein (2003, p. 28) assegura que entender significa "tomar como um todo". Prossegue:

- e dou uma ordem a alguém sinto que é suficiente dar-lhe signos. E, se recebo uma ordem, nunca digo: "Isto são apenas palavras e eu tenho de descobrir o que está por trás das palavras". E, quando, depois de eu 
perguntar algo a alguém, ele me oferece uma resposta que me satisfaz que seja justamente o que eu esperava.

- Eu não faço a objeção: "Mas essa é uma mera resposta".

Mas, se você diz: "Como vou saber o que ele quer dizer, quando não vejo nada além dos signos que ele oferece?", então, digo: "Como ele vai saber o que quer dizer, quando também ele não tem nada além dos signos?"

A obediência a uma ordem não ocorre pela decodificação de cada signo da sentença, mas pelo entendimento da sentença como um todo. Entender uma sentença é algo que acontece de forma singular do mesmo modo que ouvir uma sentença.

\section{Questão 3. O significado ultrapassa a linguagem}

Nessa questão, tratada de forma breve, Wittgenstein afirma que o significado de uma proposição é revelado por outra proposição. Ao ser proferida uma proposição, o ouvinte se inclina a perguntar ao falante o que ele "quer dizer" com as suas palavras ou se ele "quis dizer" essas palavras. Nesses termos, conforme Wittgenstein, as palavras 'entender' e 'querer dizer' referem-se a uma reação psicológica enquanto ouve, lê e profere uma sentença e, nesse sentido, entender "é o fenômeno que ocorre quando ouço uma sentença em uma linguagem familiar e não quando ouço uma sentença em uma linguagem estranha" (p. 28). O fato de 'entender' e 'querer dizer' referir-se a uma reação psicológica é porque quando queremos dizer, segundo Wittgenstein (2003, p. 29), é como se as palavras "se ligassem a alguma coisa em nós".

\section{Questão 4. Entender uma sentença}

$\mathrm{Na}$ questão 4, Wittgenstein (2003, p. 29) aproxima o entendimento de uma sentença ao de uma peça musical:

Por que esses acordes devem ser tocados exatamente assim? Por que quero produzir justamente esse padrão de variação na altura e no compasso? Gostaria de dizer: "Porque sei do que se trata". Mas do que se trata? Não saberia dizer. Como explicação, só posso traduzir a imagem musical em uma imagem de outro meio e deixar que uma imagem lance luz sobre a outra. 
As notas de um acorde são arranjadas para produzir uma variedade de sons harmoniosos. As notas isoladas nada dizem, do mesmo modo que as palavras isoladas. É preciso organizá-las formando acordes e sentenças, a partir das regras constituídas para uma coisa e outra. As palavras devem ser organizadas entre si de tal forma a construir sentenças que produzam o entendimento que o falante quer expressar. Podemos não saber explicar o processo do uso das regras de construção dos acordes e das sentenças, mas somos capazes de usar uma sentença para traduzir outra e para traduzir uma imagem musical por outra.

Prossegue:

Pense em uma natureza morta e imagine que não conseguíssemos vê-la como uma representação espacial e víssemos apenas fragmentos e linhas na tela. Poderíamos dizer, nesse caso, "não entendemos o quadro". Mas dizemos a mesma coisa em um sentido diferente quando, apesar de vermos a imagem espacialmente, não reconhecemos os objetos espaciais como coisas conhecidas, como livros, animais e garrafas. Suponha que o quadro seja um quadro de gênero e que as pessoas nele tenham cerca de uma polegada de comprimento. Se eu já tivesse visto pessoas reais desse tamanho, poderia reconhecê-las no quadro e considerá-lo uma representação delas em tamanho natural. Nesse caso, minha experiência visual do quadro não seria a mesma que tenho quando vejo o quadro da maneira normal como uma representação em miniatura, embora a ilusão de visão espacial seja a mesma em cada caso (WITTGENSTEIN, 2003, p. 29).

As diferentes experiências de ver um quadro primeiro de uma maneira, depois de outra, são comparáveis com a experiência da leitura de uma sentença com entendimento e sem entendimento.

\section{Questão 5. Entender gestos traduzidos em palavras e palavras traduzidas em gestos}

Podemos explicamos as palavras por meio de um gesto e um gesto por meio de palavras, diz Wittgenstein. Também dizemos "entendo esse gesto" no mesmo sentido em que "entendo esse tema", "ele diz algo". $\mathrm{Na}$ verdade, temos uma experiência particular dessas proposições que nos leva a chamar 'proposição' aquilo que é concebido primeiro de uma maneira e depois de outra. Isso, para Wittgenstein, gera confusões. Para ele, é como 
ler uma sentença destacada do meio da história: "Depois de ter dito isso, ele a deixou, como fizera no dia anterior". Não temos certeza se entendemos essa sentença a partir do contexto da história ou apenas enquanto familiarizados com a língua. Não a entendemos no sentido em que a entenderíamos se tivéssemos lido a história. Disso concluímos que entendemos muitas coisas diferentes e, assim sendo, é muito claro, para Wittgenstein, que o conceito de entendimento é um conceito fluido. Ele se aplica a muitas coisas diferentes.

\section{Questão 6. Entender a decodificação de uma sentença}

Wittgenstein (2003, p. 30) refina e amplia o conceito de 'entender' colocando a seguinte situação:

Apresentam-me uma sentença em um código desconhecido, juntamente com a chave para decifrá-lo, então, em certo sentido, tudo o que é exigido para o entendimento da sentença me foi dado. E, contudo, se me perguntassem se entendi a sentença, eu deveria responder: "Tenho de decodificá-la primeiro" e, apenas quando a tivesse decodificada diante de mim, como uma sentença em inglês, eu diria "agora a entendo".

A questão é saber em que momento da decodificação começa o entendimento a fim de obtermos a natureza do que chamamos 'entendimento'. A dúvida colocada é se entender uma sentença pode significar "saber o que a sentença significa", isto é, poder responder à pergunta "o que essa sentença diz?".

O nosso entendimento só pode ser expresso imperfeitamente porque não podemos nos apossar dele nem dizer a coisa final. Conforme Wittgenstein (2003, p. 31):

"Entender é algo diferente da expressão do entendimento". O entendimento não pode ser exibido; é algo interior e espiritual. - Ou "Qualquer coisa que eu faça para demonstrar entendimento, se eu repito a explicação de uma palavra, ou executo uma ordem para mostrar que a entendi, esses comportamentos não têm de ser considerados provas de entendimento". Similarmente, as pessoas também dizem "Não posso mostrar a ninguém minha dor de dente; não posso provar a ninguém que tenho dor de dente"[...]. 
Concluímos que a demonstração do entendimento é uma impossibilidade lógica.

\section{Questão 7. Entender a gramática da palavra 'significar'}

O entendimento da gramática da palavra 'significar' depende do critério usado para uma expressão ser significada dessa maneira. Quando perguntamos: "Como isto é significado?", exibimos a relação entre duas expressões linguísticas. Por isso, para Wittgenstein, a questão também diz respeito a essa relação. Nesse contexto, Wittgenstein acrescenta o processo de entendimento da sentença de uma descrição o que, para ele, é, às vezes, um processo de tradução de um simbolismo para outro; nesse caso, entender uma descrição significa fazer para si uma imagem do que é escrito.

\section{Questão 8. Entendimento de uma sentença como condição para poder aplicá-la}

Conforme Wittgenstein (2003, p. 32), só podemos agir sobre uma sentença após entendê-la, por isso não podemos obedecer a uma ordem antes de entendê-la. Sem entender a sentença não saberíamos o que fazer:

\footnotetext{
- Mas como esse saber me ajuda? Não há, por sua vez, um salto do saber para o fazer?

"Mas, mesmo assim, devo entender uma ordem para ser capaz de agir de acordo com ela" - no caso, o "devo" é suspeito. Se é um dever lógico então a sentença é uma observação gramatical?
}

Wittgenstein admite que a proposição "[...] devo entender uma ordem para ser capaz de agir de acordo com ela" faz sentido, mas não um sentido metalógico porque 'compreender' e 'querer dizer' não são conceitos metalógicos. Ele ainda admite que se "compreender uma sentença" significa, de uma maneira ou de outra, agir sobre ela, então entender não pode ser uma precondição para agirmos sobre ela. Mas, continua: a experiência pode demonstrar que o comportamento específico de entender é uma precondição para a obediência a uma ordem. 
Dois conceitos importantes emergem dessa questão: o conceito 'compreender' e 'entender'. A princípio parece que, para Wittgenstein, o agir está na dependência do compreender e não do entender, mas ele apela para a experiência e justifica 'entender' como precondição para agir. Afirma: "Não posso executar a ordem porque não entendo o que você quer dizer..."

\section{Questão 9: Entender comando e executar comando}

Nessa questão, parece que, ao entender uma ordem, algo lhe é acrescentado preenchendo a lacuna entre comando e execução. Nesse caso, trata-se de uma interpretação da ordem:

se alguém dissesse "Você entendeu? Então, não está incompleta", poderíamos retrucar "Sim, eu entendo" mas apenas porque eu acrescento algo a ela, isto é interpretação - Mas o que faz você dar justamente essa interpretação? É a ordem? Nesse caso, já era isenta de ambiguidade, uma vez que exigiu essa interpretação. Ou você vinculou a interpretação arbitrariamente? Nesse caso, o que você entendeu não foi o comando mas apenas o que fez dele (2003, p. 33).

A interpretação é algo que é dado em signos. Mas ela preenche a lacuna entre comando e execução. Se entendermos que "qualquer sentença ainda precisa de uma interpretação", estamos dizendo: nenhuma sentença pode ser entendida sem algo que lhe dê sustentação.

\section{Questão 10. "Entender uma palavra" pode significar: saber como é usada; ser capaz de aplicá-la.}

Saber, ser capaz de fazer algo, é uma capacidade que chamamos de 'estado'. Wittgenstein (2003, p. 33-4) compara proposições que descrevem estados:

Com dor de dente desde ontem.

Tenho ansiado por ele desde ontem

Tenho esperado por ele desde ontem.

Sei desde ontem que ele virá.

Desde ontem sei jogar xadrez. 
Pergunta: "Em qual das sentenças acima pode-se inserir com sensatez a palavra 'continuamente'? Comenta: Se o conhecimento é chamado um 'estado', deve ser em um sentido fisiológico ou psicológico que fala a respeito dos estados inconscientes de um modelo mental. Nesse caso, nos deslocamos do domínio gramatical dos "estados conscientes" para outro domínio. A expressão "estado consciente" não tem a mesma relação gramatical com a expressão "estado inconsciente".

Se "entender o significado de uma palavra" significa, para Wittgenstein, conhecer as regras gramaticalmente possíveis de aplicá-la, então "Como posso saber o que quero dizer com uma palavra no momento em que a emito? Afinal, não posso ter todo o modo de aplicação de uma palavra na cabeça imediatamente", mas posso ter na cabeça as regras possíveis de aplicar uma palavra como o enxadrista tem as regras do xadrez.

\section{Questão 11. Conclui a discussão da questão 10}

Portanto, para Wittgensgtein (2003, p. 34), "não devemos pensar que, quando entendemos ou queremos nos referir a uma palavra, o que acontece é um ato instantâneo depreensão da gramática, por assim dizer, não discursivo. Como se tudo pudesse ser engolido de uma só vez." "[...] quando entendemos ou queremos nos referir a uma palavra...", ocorre como se tivéssemos ferramentas na caixa de ferramentas da linguagem, prontas para uso futuro. Usamos uma palavra como usamos uma peça do xadrez. Entretanto, o xadrez mostra que há ambiguidade da palavra 'entender'.

Quando um homem que conhece as regras do jogo assiste a uma partida de xadrez, a experiência que tem, quando um movimento é executado, difere da experiência de alguém que a vê sem conhecer as regras. O conhecimento das regras do xadrez faz a diferença entre os dois espectadores. A experiência não é o conhecimento das regras, mas tanto o conhecimento das regras como a experiência, ambos são chamados 'entendimento'.

\section{Questão 12. A gramática da palavra 'entender'}

As regras da gramática, conforme Wittgenstein, podem ser entendidas como o "desempacotamento" de algo que experimentamos assim que usamos uma palavra. As questões colocadas, aqui, referem-se 
ao 'modo' de entendimento de uma sentença. Entendemos uma sentença quando a emitimos completamente ou enquanto a estamos emitindo? $\mathrm{O}$ entendimento, assim como a emissão de uma sentença, é um processo articulado e faz a articulação corresponder exatamente à de uma sentença? Ou é inarticulado, algo que acompanha a sentença da maneira como uma nota-pedal acompanha uma melodia? As respostas a essas interrogações são dadas por Wittgenstein na questão 13.

\section{Questão 13. As regras do xadrez}

A questão 13 é a questão conclusiva do capítulo I da obra citada. Conforme Wittgenstein, o xadrez se caracteriza por suas regras. Se definirmos o jogo por meio de suas regras, essas regras pertencem à gramática da palavra 'xadrez'. Isso não significa dizer que, se alguém usa a palavra 'xadrez' deve ter uma definição da palavra em mente. A pessoa só dará uma definição de 'xadrez' se lhe perguntarem o que ela quer dizer com 'xadrez'. Por analogia, o mesmo ocorre com as palavras na sentença. Usamos as palavras de forma correta ou por experiência do uso ou por conhecimento das regras. De uma forma ou de outra entendemos as palavras articuladas formando sentenças. A definição das palavras só é o caso quando somos questionados sobre elas.

\section{CONSIDERAÇÕES FINAIS}

São várias as situações de uso do termo 'entender', colocadas por Wittgenstein, para se "entender uma proposição". Colocando essa investigação no domínio da gramática, como foi o nosso propósito inicial, percebemos que Wittgenstein se inclina a dar autonomia ao uso da linguagem e mostrar que a gramática é arbitrária, apesar de ela se constituir como sendo um conjunto de regras. A gramática é arbitrária porque não leva em conta a forma da realidade. Desse ponto de vista, Wittgenstein se coloca na contramão da gramática normativa no sentido de essa caminhar em busca de uma linguagem ideal amparada no fundacionalismo lingüístico, o qual tem a visão da linguagem como um espelho da essência do mundo. 
No Tractatus (TLP, 2001, 6.13), Wittgenstein defendia uma forma alternativa de fundacionalismo linguístico quando aceitava a necessidade de uma sintaxe lógica para sustentar a descrição da realidade ou "imagem especular do mundo". Nessa obra (TLP, 2001, 5.473), as regras devem corresponder aos traços estruturais da realidade. A forma lógica dos nomes deve espelhar a essência dos objetos e a "essência da linguagem é uma imagem da essência do mundo". Essa imagem não se revela em proposições, mas em regras gramaticais.

Em Investigações filosóficas (1996, 371-3), essa ideia foi abandonada. Wittgenstein reviu os seus conceitos e assumiu a posição de que a gramática constitui nossa forma de representação, mas ela não é controlada pela realidade.

No final da Parte I de Investigações filosóficas ( $\$ 629-60$ e $\S \S 661-93)$, aparece a discussão de Wittgenstein sobre o aspecto mental de expressões verbais intencionais do tipo "crer ....", "pretender realizar .....", "querer referir-se...".

A noção de "querer dizer" que ele aplica ao significado do termo 'entender', nas questões 2 e 3 de Gramática filosófica, já aparece no Tractatus como um Método de projeção. Por exemplo: um signo proposicional "Fa" é projetado sobre um estado de coisas porque ele se faz acompanhar de uma proposição na linguagem do pensamento.

Em Investigações filosóficas, ele incluiu o significado convencional de uma palavra e o que o falante quer dizer com uma palavra em um proferimento feito conforme diferentes situações, levando em conta a forma de vida.

No segundo Wittgenstein, o que determina pretender ou querer dizer algo não são processos de pensamento, mas o ato de dirigir a atenção para o "querer dizer algo". No contexto do segundo Wittgenstein, os verbos intencionais não significam fenômenos (PI, II 217). Assim, querer dizer algo não constitui uma atividade mental.

A gramática, para Wittgenstein, não é controlada pela realidade extralinguística. Por trás de um signo não há um corpo de significado que determina seu uso correto. As regras gramaticais não decorrem dos significados. Na verdade, são as regras que constituem os significados tendo em vista que os signos não possuem significados neles mesmos. Eles adquirem significados à medida que são usados de diferentes maneiras e em diferentes contextos. 
A linguagem está imersa em formas de vida restringindo o seu uso. Por isso, entender uma proposição significa adequá-la aos vários contextos do seu proferimento, como ocorre no tratamento que ele dá à noção de 'entender' e 'entender uma proposição' nas questões de 1-12 da primeira parte de Gramática filosófica, concluindo esse tema, na questão 13, fazendo analogia com o jogo de xadrez.

\section{REFERÊNCIAS}

FAUSTINO, S. Wittgenstein: o eu e a sua gramática. São Paulo: Ática, 1995.

FINKELSTEIN, D. Wittgenstein on rules and platonism. In: CRARY, A.; READ, R. (Ed.). The new Wittgenstein. Canada: Routledge, 2000.

GLOCK, H. J. Dicionário Wittgenstein. Rio de Janeiro: Jorge Zahar, 1997.

KRIPKE, S. A. On rules and private language. Oxford: Blackwell, 2003.

MCDOWELL, J. Non-cognitivism and rule-following. In: CRARY, A.; READ, R. (Ed.) The new Wittgenstein. Canada: Routledge, 2000. p. 38-53.

WITTGENSTEIN, L. Investigações filosóficas. 2. ed. Tradução de Marcos G. Montagnoli. Petrópolis: Vozes, 1996.

Tractatus logico-philosophicus. Tradução, apresentação e ensaio Introdutório de Luiz Henrique Lopes dos Santos. São Paulo: EDUSP, 2001.

Gramática filosófica. São Paulo: Loyola, 2003. Cap. I. questões 1-13.

Recebido: 10/12/2008

Received: $12 / 10 / 2008$

Aprovado: 04/03/2009

Approved: 03/04/2009 